\title{
Public Health Financing for Adolescent and Sexual Reproductive Health: The Nigerian Case
}

\author{
Airhunmwunde Matthew Eghosa \\ Department of Accountancy, School of Business Studies, Auchi Polytechnic, Nigeria \\ Email address: \\ airhunmwunde $a$ hotmail.com

\section{To cite this article:} \\ Airhunmwunde Matthew Eghosa. Public Health Financing for Adolescent and Sexual Reproductive Health: The Nigerian Case. International \\ Journal of Health Economics and Policy. Vol. 4, No. 3, 2019, pp. 95-109. doi: 10.11648/j.hep.20190403.15
}

Received: August 11, 2019; Accepted: September 9, 2019; Published: September 21, 2019

\begin{abstract}
Health-related behaviors undoubtedly alters physical and cognitive development, which can have a repercussion on long-term health. The justification for public health financing on adolescent health as an integrated package is unequivocal. However, to date, there is still no costed plan or budget for adolescent reproductive health in many countries and so a severe lack of funding persists at all levels with no clear budgetary provision for such program. The empirical analysis was based on Nigerian six geo-political zones covering the 36 States and the Federal Capital Territory (FCT). The time series data for the variables under consideration were annual and covers the period of 1980-2014. The research explored the stationarity and cointegration properties of public health finance and adolescent reproductive health indicators. These mechanisms were reviewed for the responses to this program and finally the causality was established. The outcomes reveals that ASRH/FP is a necessity in Nigeria; PHF for adolescent reproductive health is mainly determined by many factors specifically by the amount expended by government for public health finance to total government finance and the external debt services payments in Nigeria within the study period.
\end{abstract}

Keywords: Public Health Finance, Adolescent, Sexual Reproductive Health, Nigeria, Family Planning

\section{Introduction}

Adolescent and Sexual Reproductive Health, (ASRH) and Family Planning (FP) has come of age and there is belatedly a sense of exigency that action is necessary now to make a palpable difference to the health of adolescents. Undoubtedly, there is plethora of ideas to build on. Adolescence is a compelling stage in human development, with swift psychosocial and biological changes and it is often a cycle of experimentation and risk-taking. Health-related behaviours undoubtedly alters physical and cognitive development, which can have a repercussion on long-term health [1]. These components have overtones for the types of public health financing that adolescent's need [2]. Notwithstanding, little is known about the impact of public health financing choices on adolescents, a group rarely mentioned in the ongoing discussions in many countries health coverage.

Adolescents are neither children nor adults; two groups that health systems clearly distinguish. They are persons aged $10-19$ years - accounts for 1.2 billion or $18 \%$ of the world's population [3]. Over 30 million Nigerians are between the ages of 10-19 years and nearly one-third of Nigeria's total population is between the ages of 10-24 years i.e. about 60 million people [4]. More than half of all new reproductive health, $(\mathrm{RH})$ issues occurs in people under this age bracket with girls disproportionately affected [5]. They therefore risk falling into a policy gap where their specific needs are overlooked.

Over the past two decades, there has been an avalanche of reports [6] advocacy documents [7] declarations [8] and breakthrough publications in academic journals [9] dedicated to the health and development of adolescents. There are international goals and targets directed to young people [10] and adolescent and youth are crucial to on-going discussions [11] and emerging public health agendas [12] to the plans and arrangement for the International Conference on Population and Development (ICPD) Beyond 2014 [13] and, progressively, to consultations about the post- 2015 Millennium Development Goals, (MDGs) [14]. Similarly, there has also been considerations to adolescents in global public health conferences and young people have been the focal point of considerable recent United Nations initiatives 
[15] and resolutions [16]. Perhaps, progress has been made in generating enthusiasm and commitment for adolescent health at global [17], regional [18] and increasing, national milieu [19]. Consequently, the World Bank has focused its radar on 57 countries including Nigeria [20] and has committed US\$ 5 billion on MDG targets 4 \& 5 (including RH) [21]. However, high burden regions of Africa, South Asia and Latin America has been the main focus of World Bank funding with a large chunk of the allocated fund earmarked for RH. For example in Africa, of US\$ 1.14 billion (US\$ 501 million were for $\mathrm{RH}$ ); in South Asia's US\$ 1.2 billion (US\$ 368 million were for RH); and in Latin America, of the US\$ 1.51 billion allocated (US\$ 808 million was for RH). Correspondingly, as a result of this five-year plan, over 70 per cent of all on-going World Bank health projects are ASRH/FP [22].

Regardless of worldwide efforts to promote the rights of adolescents and end child marriage [23], one-third of young women in developing countries other than China marry before age 18 [24]. Sadly, early marriage is even more common among women who are rural, less educated and poor (like in Northern parts of Nigeria) than among their urban, better educated and wealthier peers [25]. Those who marry young often want a child or feel pressured to have one; thus, their contraceptive use tends to be low.

\section{Literature Review}

Indeed many of the earlier studies focused on public and private financing for ASRH [26]. Some concentrated on outof-pocket financing [27], others deliberated on donor funds [28], use of vouchers [29], many more barely focused on public health financing with specific package in ASRH [30], while some others considered international perspective [31] and deliberated on developing countries but did not focus on Nigeria [32]. Researchers who attempted to focus on Nigeria researched on specific region and states in Nigeria [33] neglecting other states and the country at large. Against this background, this paper breaks new ground by investigating the many issues on public health financing for ASRH/FP in Nigeria.

\subsection{The Justifications of ASRH/FP in Nigeria}

Despite the comprehensive policies and programmes in place since 1994, ASRH/FP services have been dismal with severe financial challenges especially in developing countries. The Sub-Sahara African (SSA) countries including Nigeria have made the fewest strides to achieve the universal access to RH [34]. While a substantial number of these countries has indicated and alleged insufficiency in government funding and difficulties in mobilizing other domestic resources [35], others have solely relied on out-ofpocket expenditure for ASRH [36] and/or highly dependent on external donor funding flow - a source that is more uncertain than ever in the current unsettled global economic climate [37]. With the termination of the target date for achieving the MDGs of ASRH/FP services [38], assessing, financing, mobilizing, utilizing, and allocation of public health financing for ASRH/FP has remained a daunting challenge for Nigeria and many other developing countries of the world [39].

To date, there is still no costed plan or budget for ASRH and Nigeria's Federal, State and Local Government are yet to allocate specific funds in their yearly budgets for this service and so a severe lack of funding persists at all levels with no clear budgetary provision for programming on ASRH needs [40]. The bulk of funding available for ASRH programming is provided by international donor organizations [41] with minimal financial input from existing budget lines in the ministry. Although the Federal government of Nigeria (FGN) through the Federal Ministry of Health (FMOH) does provide limited funding for the promotion of certain areas of ASRH program, however, there is no evidence of a budgetary allocation specifically for the program [42]. Thus, programming is on these organization's terms and usually at pilot level, never at scale. Similarly, poor coordination among governmental and non-governmental stakeholders plagues existing programmes [43] resulting in very limited impact.

Additionally, the absence of an annual budget line for ASRH in the federation does not enable effective implementation of the policy. Where funds are released for ASRH and some related activities, it is from other health related budget lines. Myriads of supporting policies available on paper, are yet to be translated into meaningful programme interventions [44]. Notably, key programmes such as the National Family Life and HIV/AIDS Education (FLHE) curriculum, National Youth Policy, National Health Policy, National School Health Policy were widely adopted in 34 of the 36 states, yet implementation in terms of training, text, teaching, remains very poorly resourced despite national policy endorsement [45]. The bulk of existing programmes (which are competing for space in the Nigerian health lexicon) are focused on selected adolescents in school, and very meager number targets out-of-school adolescents, married adolescents, adolescents in difficult circumstances, or those adolescents in rural areas [46].

\subsection{The Structure and Trend of ASRH in Nigeria}

According to Ichoku and Okoli, the current population structure of the country is relatively young; Nigeria could be seen as a growing middle class. A growing middle class and the higher medical tests of this class and their children will require a sustainable increase investment in the health sector, otherwise, a growing middle class will in the long run culminate to increase in ageing population -another impending health care expenditure [47].

Subsequent to the oil boom in the oil industry of the late 1970 s and the accompanied bubble burst of the 1980s, health service financing has reduced in its budgetary provisions. Some researchers acknowledged that the provisions made in the budget rarely exceeded 3 percent of the total budgetary expenditures [48]. For example, Central Bank of Nigeria clearly illustrated how the share of PHF improved to only $2.6 \%, 1.96 \%, 2.99 \%, 1.95 \%, 2.5 \%$ in $1996,1997,1998$, 
1999, and 2000 respectively [49]. A large chunk of the budget was used for personal cost [50]. UNDP, revealed that the health spending made by government was lower than $0.2 \%$ of GDP [51] compared to Sachs, et al. acknowledgement of $1 \%$ standard prearranged by the Commission on Macroeconomics and Health in addition to the 15 percent annual national budgeted specified in the Abuja Declaration of 2001 [52].

PHF has repeatedly been described as insufficient with a health provision in the budget hardly exceeding half of the recommended health budget in the world [53]. While there are many undesirable issues in the Nigerian health sector needing attention at the moment, the present situation in Nigeria's PHF reflects a meager US $\$ 80$ per capita [54]. The challenge has been lower budgetary allocation to the health sector which are a product of limited fiscal space and low domestic resource mobilization capacity which inhibits the government from significantly increasing the level of resource allocation to these health sector [55].

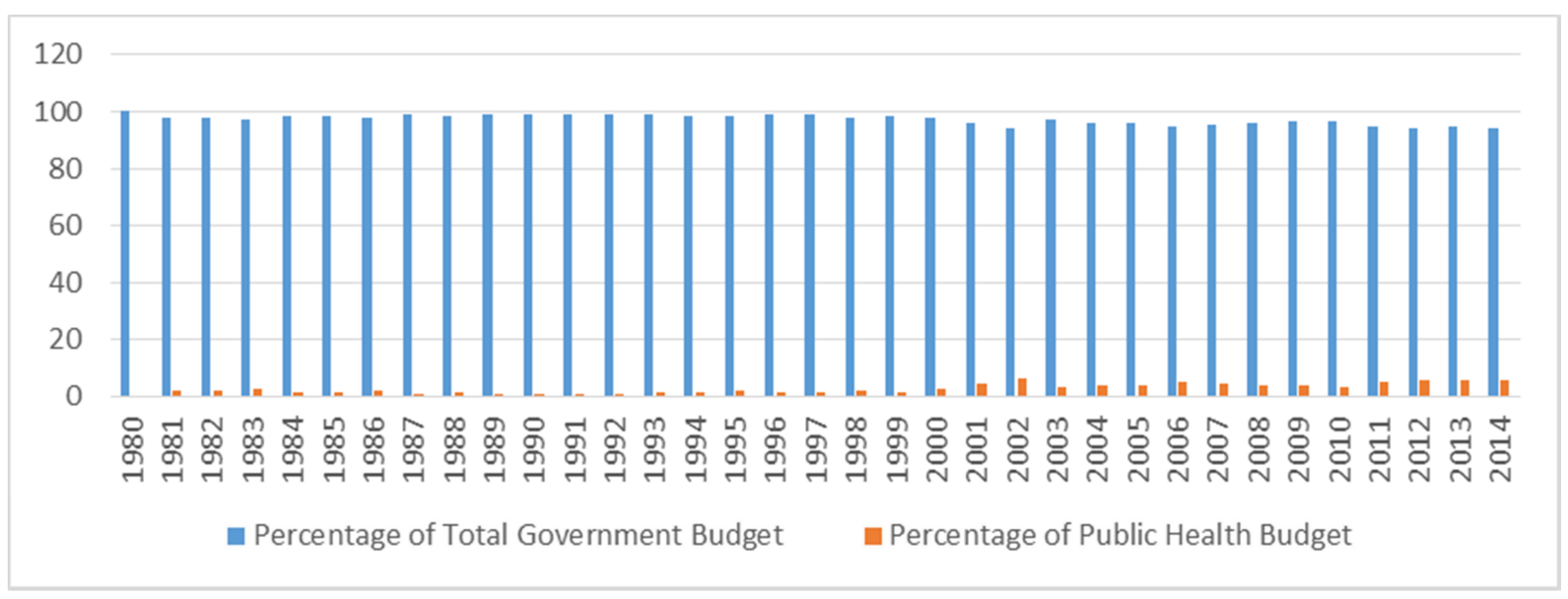

Figure 1. Allocation of PHF in the Total Budget.

\subsection{The Resolution to ASRH}

In view of these, understanding the factors that contribute to trends in public health financing is a sensitive issue, especially the role of ministries of finance. Although ministries of health seem to be committed to up-surging the size of health budgets, ministries of finance have sometimes however reduce health finance particular for other government expenditure [56]. Therefore, knowing where, to whom, and when to finance ASRH/FP is key to ensuring a smooth and adequate flow of funds at both the national and sub-national levels. Mobilizing these resources and ensuring that commitments translate to actual spending remain a constant challenge for family planning program managers and advocates in developing countries. Financing ASRH/FP services require significant commitments as well as efficient and effective use of finance resources.

To properly tackle these issues, government will first need to understand how much has been or is currently spent on ASRH/FP and what exactly those funds are being spent on. More and more, advocates for ASRH/FP draw on a wide spectrum of analytical tools and data sources to intensify the case for public health financing for ASRH/FP programs. One approach to address this key policy questions are ASRH/FP sub-accounts [57]. Like other areas such as child health, malaria and HIV/AIDS for which data are collected for review processes as part of the overall National Health Account (NHA) of any country, ASRH account should be embedded for program monitoring and for policy formulation and implementation. Since NHA, is globally acceptable and recognized tool for tracking the flow of funds through a country's health systems -beginning from their financing sources to the end users [58], the RH subaccounts are additional and more detailed description to assess SRH expenditure data that will guide the mobilization, utilization and allocation of the limited resources among various needs [59]. Unfortunately, many developing countries are yet to implement the NHA, and those who have implemented the NHA such as Nigeria, are bereft of the RH subaccounts.

Therefore, the study specifically attempts to confront the problem - the absence of costed plan or clear budgetary provisions for ASRH and the determinants of public health financing for ASRH in Nigeria.

\section{Model and Methodology}

\subsection{The Theoretical Framework}

The objective of this research paper is to examine the dynamism of public health finance for ASRH in Nigeria. Based on the theoretical framework of cost accounting, demand side position, supply side components, developmental theory and their available data, some groups of predicted variables were identified.

These are the health stock, income and economic variables [60-62], demographic, and epidemiology changes [63], demand side effects [64], institutional factors [65] and supply side effects [66]. Health is portrayed as a stock which degenerates over time in the absence of investments in health, such that health is seen as a sort of capital. Health is therefore a consumption good (that yields direct satisfaction and utility) as well as investment good (which yields 
contentment to consumers circumlocutory through upsurge in productivity, income and few sick days. Demographic and epidemiology transitions describe the size and structure of the population, patterns of population age distributions, fertility, mortality, causes of deaths and life expectancy. The institutional factors refers to a nations political and social institutions that brings changes in trade barriers, government budgets and deficits, exchange rates, etc. While the demand side effects describe all areas of the economy in relation to the purchase and use of health services in the economy, the supply side effects on the other hand expresses areas of the economy up to and including the provision and retail of health services in the economy.

These variables were decomposed, reclassified with modification and combined based on preceding literatures to depict real per capital income of GDP, recurrent and capital expenditure of health, ratio of public health finance to total government finance, population of adolescent under 19 years, and external debt service payments. The empirical analysis is carried out using 36 annual observations for each variable over the period 1980-2014.

\subsection{The Hypothesis}

Given the theoretical framework discussed above, the determinants for public health financing for ASRH can be expressed as a function of real per capital income of GDP, capital expenditure of health, recurrent expenditure of health, ratio of public health finance to total government finance, population of adolescent under 19 years, and external debt service payments. Therefore, the following hypotheses have been developed for the present study:

\section{Hypothesis 1}

$\mathrm{H}_{10}$ : Capital health expenditure is a determinant of PHF. PHF.

$\mathrm{H}_{11}$ : Capital health expenditure is not a determinant of

Hypothesis 2

$\mathrm{H}_{20}$ : External debt servicing is a determinant of PHF.

$\mathrm{H}_{21}$ : External debt servicing is not a determinant of PHF.

Hypothesis 3

$\mathrm{H}_{30}$ : The population of adolescent under 19 is a determinant of PHF.

$\mathrm{H}_{31}$ : The population of adolescent under 19 is not a determinant of PHF.

\section{Hypothesis 4}

$\mathrm{H}_{40}$ : Recurrent health expenditure is a determinant of PHF.

$\mathrm{H}_{41}$ : Recurrent health expenditure is not a determinant of PHF.

\section{Hypothesis 5}

$\mathrm{H}_{50}$ : The real per capital income of GDP is a determinant of PHF.

$\mathrm{H}_{51}$ : The real per capital income of GDP is not a determinant of PHF.

Hypothesis 6

$\mathrm{H}_{60}$ : The ratio of public health finance to total government finance is a determinant of PHF.

$\mathrm{H}_{61}$ : The ratio of public health finance to total government finance is not a determinant of PHF.
These hypotheses gives rise to the empirical specification of public health financing regression equation as stated below.

\subsection{The Model}

The following model is specified for the empirical analysis:

LnPHFt $=\alpha 0+\alpha 1 \operatorname{lnCEXPt}+\alpha 2 \operatorname{lnEXDEBTSt}+\alpha 3 \ln P O P 19 t$

$+\alpha 4 \operatorname{lnREXPt}+\alpha 5 \ln R P C G D P t+\alpha 6 \operatorname{lnRPTt}+\mathrm{Ut}$

Where:

LnCEXP: Log of public health finance.

LnEXDEBTS: Log of external debt servicing.

LnPOP 19: Log of population of adolescents under 19 year.

LnREXP: Log of recurrent health expenditure.

LnRPCGDP: Log of real per capita gross domestic product.

LnRPT: Log of the ratio of public health finance to total government finance.

Notably, the apriori expected signs from the regression (1) is estimated as follows:

$$
\mathrm{X} 1>0, \mathrm{X} 2<0, \mathrm{X} 3>0, \mathrm{X} 4>0, \mathrm{X} 5>0, \mathrm{X} 6>0 \text {. }
$$

\subsection{Estimating Methodology}

The research explores the stationarity and cointegration properties between PHF and ASRH indicators using Augmented Dickey-Fuller (ADF) test, Johanson and Juselius Cointegration tests and the Vector Error Correction Mechanism (VECM).

The Unit Root Test results were conducted by applying the ADF test to check for spurious correlation between variables in the regression equation. This is because most of the time series data are usually non-stationary in nature and as a result, a simple ordinary least square (OLS) regression analysis for such data engenders spurious outcomes. The Dickey-Fuller (DF) test [67] is commonly used because it assumes only one unit root in the process [68] and demands estimation. The ADF involves running a regression for each considered series with first lagged level, or the lagged first differences as independent variables or the second lagged differences. It takes the following form:

$$
\Delta \mathrm{Y}_{\mathrm{t}}=\alpha_{0}+\alpha_{2} \mathrm{Y}_{\mathrm{t}-1}+\sum \alpha_{1} \Delta \mathrm{Y}_{\mathrm{t}-1}+\mathrm{U}_{\mathrm{t}}
$$

Where $\Delta$ is the first difference operator. In essence, the equation connotes that the series $Y_{t}$ possesses both a stochastic and deterministic trends. The p lagged difference terms $\mathrm{Y}_{\mathrm{t}-1}$ are used to approximate the structure of the error, and the value of $\mathrm{P}$ is set so that the $\mathrm{U}_{\mathrm{t}}$ is serially uncorrelated. The error term is also homoscedastic and the specification of the deterministic terms depends on the assumed behavior of $Y_{t}$. Although the DF test assumes that the error term $U_{t}$ to be a white noise, however, this is unlikely in most cases and therefore the problem of autocorrelation in the residuals occurs in estimating (2).

According to Asteriou and Hall, where there are more than two variables in the model, then there is a likelihood of 
having more than one co-integrating vector [69]. This means that the variables in the model might form several equilibrium relationships. Thus, for a $\mathrm{K}$ number of variables, there could be only up to K-1 cointegrating vectors. Finding how many cointegrating relationships is inherent among $\mathrm{k}$ variables necessitates the use of Johanson's approach. This is similar to the Engle-Granger approach, where all variables in the system are integrated of the same order [70]. It therefore follows that a group of variables $X_{t}$ will be assumed to be cointegrated when the linear combination of the variable will produce a stationary process. This means that for any regression connection to be healthy and momentous the different series must be cointegrated, else, the equation will maintain its unit root properties and result in misleading and spurious regression. Therefore, this research has adopted a maximum possibility test procedure in the chronology of Johansen and Juselius. The theory of multivariate cointegration, as advocated and promulgated by Johansen and Juselius provides a link among integrated processes and the notion of long run equilibrium. One of the reasons for this choice is because this technique is a vector autoregrssion (VAR) based and evidence abound that it is better than the alternative multivariate method and the single equation. Explicitly, the cointegration test begins with a test for the number of cointegrating connection or rank (r) of $\pi$ by applying Johansen's maximal Eigen value of the stockastic matrix and the Likelihood Ratio (LR) test constructed on the trace of the stochastic matrix $\pi$ which is the long-run multiplier matrix of $\mathrm{m} \mathrm{X} \mathrm{n}$ known as the matrix coefficient. Precisely, if $Y_{t}$ is a vector of $n$ stochastic variables, then there exist a P-lay VAR with Gaussian error of the following order:

$$
\mathrm{Y}_{\mathrm{t}}=\mu+\Delta 1 \mathrm{Yt}-1+\ldots \ldots \ldots \ldots+\Delta \mathrm{PYt}-\mathrm{p}+\Sigma
$$

Where $Y_{t}$ is an $n \times 1$ vector of variables that are integrated of order frequently alluded as (1) and $\Sigma_{t}$ is an $n X 1$ vector of innovation. Then VAR can therefore be written as:

$$
\Delta \mathrm{y}_{\mathrm{t}}=\mathrm{u}+\mathrm{nyt}-1+\sum_{i=1}^{p-1} \mathrm{r} 1 \Delta 1 \mathrm{yt}-1+\sum_{\mathrm{t}}
$$

Where $\pi=\sum_{i=1}^{p} A i-1$ and $\mathrm{Ti}=-\sum_{i=1}^{p} A_{j}$.

In a broader sense, five distinct models can be considered even though the first and the fifth are considered unrealistic. They include where there is no intercept or trend in $\mathrm{CE}$ (cointegrating equation) or $\operatorname{VAR}(\delta 1=\delta 2=\mu 1=\mu 2=0)$; where there is intercept (no trend) in $\mathrm{CE}$, no intercept or trend in $\operatorname{VAR}(\delta 1=\delta 2=\mu 2=0)$; where there is intercept in $\mathrm{CE}$ and VAR, no trend in $\mathrm{CE}$ and $\operatorname{VAR}(\delta 1=\delta 2=0)$; where there is intercept in CE and VAR, linear trend in CE, no trend in VAR $(\delta 2=0)$; and where there is intercept and quadratic trend in CE, intercept and linear trend in VAR.

However, some researchers proposed two kinds of statistical test with the aim to determine the number of cointegration matrix [71-72]. As noted earlier, the first is the trace test depicted as ( $\lambda$ trace). Its function is to test the null hypothesis that the number of dissimilar cointegrating vector is less than or similar to q against an unrestricted alternative $\mathrm{q}=\mathrm{r}$ the best calculated. This means that it is based on the ordered (estimated) Eigen value in the equation below:

$$
\text { Trace }(\text { ro } / k)=-T \sum_{i r-r o+1=0}^{k} \ln (1-\lambda)
$$

Where $\lambda \mathrm{i}=$ ordered (estimated) Eigen value from the matrix, $\mathrm{T}$ is the number of usable observations. The test is the relevant test statistics for the null hypothesis $r \leq$ ro as against the alternative $r \geq$ ro +1 following a sequence.

The other statistical test is the maximum Eigen value test $(\lambda \max )$ statistics and represented as:

$$
\lambda \max (r, r+1)=-T \ell n(1-\lambda r+1)
$$

This test permits the contrast of a cointegrating rank of $r$ against the alternative of a cointegrating rank of $r+1$. Consequently, this can be repeated for larger values of $r$ until it fails to reject the null hypothesis.

The third stage in the data analysis that will be adopted is the VECM which presents a likelihood to apply VAR to a unified multivariate time series even though spurious regression stands as one of the main problems in the application of VAR to integrated time series such as those connected with t-statistics that are highly significant and Rsquared that is high even when there exist no relationship between the variables [73]. The Johanson theorem exemplication sets up formally the theoretical basis for the VECM whose ensues after determining the optimal lag length and the number of cointegrating vectors. Generally, once a cointegration has been detected between series, it becomes obvious that there exist a long-term equilibrium relationship between them. In such cases, the VECM is applied so as to be able to estimate the short-run properties of the cointegrated series. However, where there is no cointegration in the series, then the VECM becomes irrelevant and the Granger causality test is directly proceeded to so as to establish causal links between the variables. The regression equation pattern for VECM is as outlined below as:

$$
\begin{aligned}
& \Delta Y 1=\alpha 1+p 1 e 1+\sum_{i=0}^{n}{ }_{\beta} 1 \Delta Y 1-t+\sum_{i=0}^{n} \delta 1 \Delta X t-1+\sum_{i=0}^{n} \gamma 1 Z t-1, \\
& \Delta X 1=\alpha 2+p 2 e 2+\sum_{i=0}^{n}{ }_{\beta} 1 \Delta Y 1-t+\sum_{i=0}^{n} \delta 1 \Delta X t-1+\sum_{i=0}^{n} \gamma 1 Z t-1
\end{aligned}
$$

The cointegration rank shows the number of cointegrating vector in VECM such that a rank of three connotes that three linearly independent combinations of the non-stationary variable will be stationary. Meanwhile, in (7), a negative and significant coefficient of ECM $\left(\mathrm{e}_{\mathrm{t}-1}\right)$ depicts that any shortrun variations between the explanatory and predicting variables will result to a stable long-run relationship between the variables. 


\section{Estimation and Analysis}

\subsection{Unit Root Analysis}

Generally, most macroeconomics time series contain unit roots test that are portrayed by the presence of stochastic trends [74]. The unit root test started with the testing of the order of integration for each series under investigation
(LnCEXP, LnEXDEBTS, LnPHF, LnPOP19, LnREXP, LnRPCGDP, \& LnRPT) in order to circumvent the spurious regression phenomenon [75]. The univariate properties of these variables were initially estimated using the ADF unit root test [76] at level I (0) results under $1 \%, 5 \%$ and $10 \%$ critical values and the assumption of a constant and trend with constant as shown in Table 1.

Table 1. Unit Root Test.

\begin{tabular}{|c|c|c|c|c|c|}
\hline \multicolumn{6}{|l|}{ ADF Test } \\
\hline \multirow{2}{*}{ Variables } & \multicolumn{2}{|l|}{ Level } & \multicolumn{2}{|c|}{ First Difference } & \multirow{2}{*}{ Conclusion } \\
\hline & Constant & Constant \& Trend & Constant & Constant \& Trend & \\
\hline LnCEXP & $-2.981038^{*}$ & -3.233456 & $-3.646342 * * *$ & $-3.238054 *$ & $\mathrm{I}(1)$ \\
\hline LnEXDEBTS & $-2.614300^{*}$ & -3.207094 & $-3.646342 * * *$ & $-4.262735^{* * *}$ & I (1) \\
\hline LnPHF & $-2.615817^{*}$ & -3.207094 & $-3.646342 * * *$ & $-4.262735^{* * *}$ & I (1) \\
\hline LnPOP19 & $-2.615817 *$ & -3.209642 & $-3.646342 * * *$ & $-4.262735^{* * *}$ & I (1) \\
\hline LnREXP & $-2.614300^{*}$ & -3.207094 & $-3.646342 * * *$ & $-4.262735 * * *$ & I (1) \\
\hline LnRPCGDP & $-2.614300 *$ & -3.207094 & $-3.646342 * * *$ & $-4.262735^{* * *}$ & I (1) \\
\hline LnRPT & $-2.614300 *$ & -3.207094 & $-3.646342 * * *$ & $-4.262735^{* * *}$ & I (1) \\
\hline
\end{tabular}

Where $(* * *),(* *)$, and $(*)$ represents $1 \%, 5 \%$, and $10 \%$ significant level.

Regardless of the length of lag, the results and outcome of the ADF unit root test in the order of first-difference showed that all the variables on constant and constant with trend are stationary. This implies that the null hypothesis can be overwhelmingly rejected for all the variables since they were not characterized by unit root glitches. This indicates that the shock in all variables (LnCEXP, LnEXDEBTS, LnPHF, LnPOP19, LnREXP, LnRPCGDP, \& LnRPT) were not persistent. The estimated variables can therefore be surmised in the order of integration I (1). Having established that all the variables were stationary at first level difference, a necessitous condition for conducting a cointegration test was met.

\subsection{Lag Selection}

An important aspect in cointegration test is to ascertain the unrestricted lag structure of the VAR system which are commonly used in analysis for the effects of shock. In VAR models specification, determination of the VAR lag length is very critical which has been demonstrated to show the estimates of VAR whose lag length is in contrast to the true VAR [77]. The choice of lag structure in the VAR system according to Hall is important because too many lags specified (that is an overfitting) will consume more degree of freedoms leading to small sample issues or what could be term mean-square forecast errors of the VAR [78]; while too few lags (that is underfitting) may engender serial correlation glitches [79]. Hence, finding the precision for VAR models is significant even though Hafer and Sheehan maintained that this precision varies considerably for lag lengths alternatives. Indeed, most VAR model are projected with the use of symmetric lags (rather than asymmetric lag) for all variables in all the derived equations by an unequivocal statistical criterion such as the Akaike's information criterion (AIC), Schwarz's information criterion (SIC), and Hannan-Quinn information criterion (HQ) [80]. Basically, when estimation is performed with the different number of lag, a comparison is made with the entire criterion which is usually lowest; the most frequent tend to represent the chosen lag.

Table 2. Lags Selection.

\begin{tabular}{llll}
\hline Number of Lags & AIC & SIC & HQ \\
\hline 0 & 240.8509 & 241.1715 & 240.9572 \\
1 & 233.0913 & 235.6563 & 233.9415 \\
2 & 230.0171 & 234.8265 & 231.6113 \\
3 & $223.0803^{*}$ & $230.1342 *$ & $225.4185^{*}$ \\
\hline
\end{tabular}

* Indicates lag order selected by the criterion.

Table 2 above presents the values of AIC, SIC, and HQ with the different number of lags. It could be seen that the optimal VAR system for multivariate Johanson-Juselius cointegration test have been ascertained by minimizing the system-wise and therefore all the criteria used pointed to three lags (where the values were lowest) and this has been adopted for the cointegration test. Nonetheless, where there is no serial correlation however, it means the second lowest value can also be considered as the lag selection.

\subsection{Cointegration Test}

Given that the unit root test shows a stationarity in all variables, it becomes germane to evaluate any possible cointegration among these variables by employing the Johansen-Juseliu cointegration test or the reduced rank procedure [81]. Generally, Johanson cointegration test will help to spot a number of cointegration vectors in nonstationary time series by allowing for hypothesis testing regarding the element of cointegrating vector and loading the matrix. The results of the Johansen-Juselius cointegration test equation estimated using the Trace test and Eigen value statistics are presented below: 
Table 3. Johanson-Juselius Multivariate Cointegration Rank Test at 5\%.

\begin{tabular}{|c|c|c|c|c|c|c|c|c|c|}
\hline \multicolumn{5}{|l|}{ Trace } & \multicolumn{5}{|c|}{ MaxEigen } \\
\hline Но & Hi & Stat & $5 \%$ & $\mathbf{P}$ & Ho & $\mathbf{H i}$ & Stat & $5 \%$ & $\mathbf{P}$ \\
\hline $\mathrm{r}=0$ & $r=0$ & 347.2377 & 95.75366 & 0.0000 & $r=0$ & $\mathrm{r}=0$ & 203.4311 & 40.07757 & 0.0001 \\
\hline$r=1$ & $r \leq 1$ & 143.8066 & 69.81889 & 0.0000 & $r=1$ & $\mathrm{r}=1$ & 68.58678 & 33.87687 & 0.0000 \\
\hline$r=2$ & $r \leq 2$ & 75.21978 & 47.85613 & 0.0000 & $\mathrm{r} \leq 2$ & $r=2$ & 32.27721 & 27.58434 & 0.0115 \\
\hline$r=3$ & $r \leq 3$ & 42.94257 & 29.79707 & 0.0009 & $r \leq 3$ & $\mathrm{r}=3$ & 21.07083 & 21.13162 & 0.0510 \\
\hline$r=4$ & $r \leq 4$ & 21.87174 & 15.49471 & 0.0048 & $\mathrm{r} \leq 4$ & $r=4$ & 15.75350 & 14.26460 & 0.0289 \\
\hline$r=5$ & $\mathrm{r} \leq 5$ & 6.118243 & 3.841466 & 0.0134 & $\mathrm{r} \leq 5$ & $\mathrm{r}=5$ & 6.118243 & 3.841466 & 0.0134 \\
\hline
\end{tabular}

The cointegration test presented in Table 3 above showed that both the Trace and maximal Eigene test statistics strongly reject the null hypotheses (from $r=0, r \leq 1$ to $r \leq 4$ ) that there is no cointegration vector present. This implies that all the variables are bounded together by a long-run relationship which confirms the convergence of the presence of a stable long-run equilibrium relationship among the series hence suggesting the possibility of a VECM to represent the association between the independent and the dependent variables. Subsequently, the demonstration of cointegration connotes that all the identified determinants would sway health finance for adolescent's reproductive health in the long-run as can be seen in the table below.

Table 4. Normalized Cointegration Coefficient (standard error in parentheses).

\begin{tabular}{|c|c|c|c|c|c|}
\hline LnPHF & LnEXDEBTS & LnPOP19 & LnREXP & LnRPCGDP & LnRPT \\
\hline 1.000000 & $\begin{array}{l}0.427194 \\
(0.00621)\end{array}$ & $\begin{array}{l}3.481416 \\
(0.05039)\end{array}$ & $\begin{array}{l}-1.886815 \\
(0.01226)\end{array}$ & $\begin{array}{l}2.134386 \\
(0.03100)\end{array}$ & $\begin{array}{l}-0.105222 \\
(0.01088)\end{array}$ \\
\hline
\end{tabular}

The normalized equation from Table 4 is given by:

$$
\text { LnPHF }=-0.427194 \operatorname{LnEXDEBTS}-3.481416 \operatorname{LnPOP} 19+\text { 1.886815LnREXP }-2.134386 \operatorname{LnRPCGDP}+\text { 0.105222LnRPT }
$$

As can be seen in Table 4, all the variables (except for recurrent health expenditure and the rate of PHF to total government finance) showed a negative coefficient. This suggest that recurrent health expenditure and the rate of PHF to TGF are inversely related to public health finance in the long-run compared to external debts service, population of adolescent under 19 and real per capita income of GDP which showed a corresponding positive sign. Meaning that as public finance increases, both negative values will be depleting and vice versa compared to the other three variables that reflected a positive sign.

\subsection{Vector Error Correction Model (VECM)}

The demonstration of cointegration above depicts that PHF will be swayed by all the identified determinants in the longrun. Short-run dynamic modelling like VECM is usually performed by utilizing the general or specific modelling approach [82]. The idea is to unravel the essential variables in the short-run as a potential policy measure by relating the short run changes in the dependent variable (LnPHF) to the short run changes in the explanatory variables (LnEXDEBTS, LnPOP19, LnREXP, LnRPCGDP, LnRPT), thereby linking these with the alterations to the long-run effect through the feedback mechanism. The results of the short-run dynamic model are presented in Table 5.

Table 5. Vector Error Correction Model.

\begin{tabular}{|c|c|c|c|c|}
\hline Variable & Coefficient & Standard Error & t-Statistics & Probability \\
\hline $\mathrm{C}$ & 0.288271 & 0.13829 & 2.08460 & \\
\hline $\operatorname{ECM}(-1)$ & -0.169153 & 0.24546 & -0.68912 & 0.0016 \\
\hline D (LnEXDEBTS) & -0.499718 & 0.11697 & -4.27236 & 0.0006 \\
\hline D (LnPOP19) & -1.335251 & 1.89964 & -0.70290 & 0.4922 \\
\hline D (LnREXP) & 0.171514 & 0.25807 & 0.66460 & 0.5158 \\
\hline D (LnRPCGDP) & 0.412287 & 1.05899 & 0.38932 & 0.7022 \\
\hline $\mathrm{D}$ (LnRPT) & 0.870544 & 0.30544 & 2.85013 & 0.0116 \\
\hline
\end{tabular}

\begin{tabular}{ll}
\hline R-squared & 0.871950 \\
Adjusted R-squared & 0.751904 \\
S. E. of regression & 0.264774 \\
Prob (F-statistic) & 0.000147 \\
Durbin-Watson stat & 1.864879 \\
\hline
\end{tabular}

The hypothesis for the variables $-\mathrm{H}_{31}, \mathrm{H}_{41}$, and $\mathrm{H}_{51}$ (except for external debt servicing $\left[\mathrm{H}_{20}\right]$ and the ratio of PHF to TGF $\left.\left[\mathrm{H}_{60}\right]\right)$ showed an insignificant result since their $\mathrm{p}$-value were all more than $5 \%$. This means that those variables were tolerably insignificant to explain public health finance while the external debt servicing and the ratio of PHF to TGF were adequately significant to explain PHF. Overall, the equation could be said to have performed well because of the error 
correction coefficient or adjustment coefficient otherwise known as the speed of adjustment and the corresponding significant value. This accounts for why it is able to correct the disequilibrium of the system which is its major task. However, the research data are annual in nature such that the speed and direction of adjustment at which she is correcting the disequilibrium is annual by the reported amount. This means she is adjusting with the previous period disequilibrium at the above rate. The error correction coefficient also possesses two good attributes - not only that it had a negative sign (in the right direction to restore the long-run relationship) but also that it was awfully significant because of the p-value which also connotes an acceptance of the cointegration hypothesis. Besides, this depicts the validity that both the explanatory and predicting variables possesses a long-run equilibrium causality.

Clearly, the regression results shows that the hypothesis test for external debt servicing and the ratio of public health finance were significant $\left(\mathrm{H}_{20}, \mathrm{H}_{60}\right)$ and key determinants for public health finance while the hypothesis test for population of adolescent under 19, the recurrent health expenditure and the real per capital income of GDP were insignificant $\left(\mathrm{H}_{31}\right.$, $\mathrm{H}_{41}$, and $\mathrm{H}_{51}$ ) and were not key determinants of public health finance. In the short-run however, Wald Statistic have been adopted to verify the relationship between the independent and the dependent variables.

\subsection{Granger Causality Test: Wald Statistics}

In order to test for the short-run relationship on whether the independent variables can cause changes in the dependent variable, the Wald statistics has been adopted by setting up a null hypothesis with the lagged values of coefficients in each equation which is expected to be zero. The results from each of the independent variable Wald test following the chisqaure distribution instead of $\mathrm{F}$ distribution are presented below.

Table 6. Wald Test Coefficient Restrictions.

\begin{tabular}{lll}
\hline Variables & Null Hypothesis & P-Values \\
\hline LnEXDEBTS & $\mathrm{C}(6)=\mathrm{C}(7)=0$ & 0.0000 \\
LnPOP19 & $\mathrm{C}(8)=\mathrm{C}(9)=0$ & 0.3740 \\
LnREXP & $\mathrm{C}(10)=\mathrm{C}(11)=0$ & 0.7971 \\
LnRPCGDP & $\mathrm{C}(12)=\mathrm{C}(13)=0$ & 0.8255 \\
LnRPT & $\mathrm{C}(14)=\mathrm{C}(15)=0$ & 0.0112 \\
\hline
\end{tabular}

In Table 6 above, the Wald test coefficient shows that the chi-square probability of adolescent population, recurrent health expenditure, and real per capita income of GDP were more than $5 \%$ which means the null hypothesis $(\mathrm{C}(8)=\mathrm{C}$ $(9)=0 ; C(10)=C(11)=0 ; C(12)=C(13)=0)$ of the three variables can be rejected since they are equal to zero. It depicts that there is no short-run causality running jointly from each of the three variables to PHF. On the contrary, the chi-square probability of external debts and the ratio of PHF to total government finance were less than $5 \%$ which connotes that the null hypothesis $(\mathrm{C}(6)=\mathrm{C}(7)=0 ; \mathrm{C}(14)=$ $\mathrm{C}(15)=0)$ cannot be emphatically rejected since the equations were not equal to zero. This purports that there is short-run causality running jointly from external debts and the ratio of PHF to TGF variables to PHF. Summarily, there is long-run and short run causality in external debts servicing and the ratio of PHF to total government finance with the PHF while none exist for the population of adolescents, real per capita GDP and ratio of public health finance to total government finance.

\subsection{Diagnosis Test and Stability Check}

A diagnose on whether the model (where PHF is the dependent variable) generally have any statistical error is undertaken. This is unraveled from several elements such as its R-squared and serial correlation [83], multicollinearity [84], heteroscedasticity [85], normal distribution [86], etc. The model is assumed to be statistically error-free when its residual unfolds a high $\mathrm{r}$-squared, with no serial correlation and heteroscedasticity, and must be normally distributed. These have been tested and shown below from the estimated model in (2).

The value of R-squared 0.871950 represents $87 \%$ which is very high and represents a good score for the model. As a coefficient of determination, it depicts a statistical measure of how well the regression line approximates the real data points. The corresponding probability of F-Statistics was very significant and good for the model too. The BreuschGodfrey Serial Correlation LM Test showed a chi-square pvalue of 0.0793 which is more than $5 \%$ connoting that the model is not affected by serial correlation or its not suffering from serial correlation and this represent a desirable score for a model. The Breusch-Pagan-Godfrey test for heteroscedasticity showed an observed R-square of 0.5889 $(58.9 \%)$ which means that the model is devoid of heteroscedasticity, representing another good sign of the model. The normality test showed a Jarque-Bera probability of $0.787294(78.7 \%)$ connoting a fairly high distribution. This means that the residual of the model is normally distributed and desirable as it were.

Table 7. Diagnosis Test.

\begin{tabular}{lll}
\hline Diagnosis Test & Consideration & Value \\
\hline R-Square & R-Ssqaure/F-Statistics & 0.871950 \\
Serial Correlation & Breusch-Godfrey Chi-Square P-Value & 0.0793 \\
Heteroscedasticity & Breusch-Pagan-Godfrey Observed R-squared & 0.5889 \\
Normal Distribution & Jarque-Bera probability & 0.787294 \\
\hline
\end{tabular}

On the contrary, it should be noted that the capital health expenditure variable was removed from the model because of the issue of near linear matrix. This is not surprising because in OLS method, multicollinearity can cause various problems. In this study, it was a case of perfect multicollinearity because two of the independent variables 
(capital health expenditure and recurrent health expenditure) had a perfectly linear relationship with each other. To detect the exact variable, all the variable were estimated while omitting each of the variable one after the other [87]. This process made it impossible to estimate either variable concurrently while all other variable were kept constant. In other to fix the problem of near linear matrix, the capital health expenditure was simply removed from the model before the Johanson-Juselius cointegration test was performed [88]. Once this was done, the problem of near linear matrix was fixed.

Overall, the model has posed no problem (except for multicollinearity issue that was sorted out) and this is highly desirable having met all the condition in the diagnosis test.

\section{Discussion}

The study showed that real per capita income of GDP was not a determinant of PHF $\left(\mathrm{H}_{41}\right)$ in Nigeria and this is consistent with the apriori expectation; hence, adolescent reproductive health is a normal good. This confirms the results of several researchers [89-90] who has variously upheld that income is a normal good for health determinants. This could be attributed to an unequal distribution of wealth in Nigeria and the inability of the successive Nigerian government to give priorities to adolescent health care. However, this is inconsistent with other research [91] whose outcomes revealed that public health finance is a luxury good. This is not completely surprising based on the outcome from the short-run results where the real per capita income was insignificance. The positive sign of the real per capital income of GDP connotes the likelihood level of development of a country and its general effects on adolescent reproductive health on public health finance which is consistent with the aforementioned study. Deleteriously, if expectations of good public health upsurge beyond the actual health status of adolescents because they have more access to reproductive health care, then the perception of reproductive ill-health may increase with real per capita income. More so, it could also be that since Nigeria is a developing country, where health insurance is unavailable for majority of the populace particularly the poor, emphasis may have been placed on national resources for basic amenities like food and housing rather than investment in adolescent health. The incongruity in the results however, may be characterized as a pointer to a range of public health policies instituted by the government to improve and develop the public health sector such as the emphasis on the financing of programs that generate employment for the majority, rather than ASRH/FP.

The result of the population of adolescent under 19 was insignificant $\left(\mathrm{H}_{31}\right)$ and inconsistent with the apriori expectation. This is however consistent with the studies of [92] where no significant relationship was reported. This was because it is believed that specific health financing for respective age group should be utilized as determinant rather than the entire public health finance. Quite true! After all, other studies [93] results have depicted that public health expenditure in one period was lower in many countries depending on the age group in comparison to previous periods. This is relatively coherent in part with this study because like the real per capital income GDP, the short-run result reflected no causality between PHF and the population of adolescents. Perhaps, this may be responsible for one of the reasons why there is little or no special package for adolescent population in its entirety, despite the number of adolescent population in Nigeria. However, the result is incongruous with some other studies. The incompatibility confirms the studies of Paskawych, where the population of adolescents has the largest effect on government finances [94]. Similarly, this inconsistency also corroborates other studies [95]. This may not be surprising since the population of adolescent less than 19 years of age in Nigeria constitutes about one-third of the entire population, amounting to roughly 60 million. At this rate, projections are scary and this may undoubtedly turned out to be the peak of the determinants. The coefficient of this variable showed a negative sign depicting that public health finance has no bearing with adolescent population. It also negates the meaning that as the population of adolescents' increases yearly, the associated risk connected with ASRH increases and government become wearier and reneged on its responsibilities to implement the many policies and programmes that are competing for spaces in the archives. This study however believes that the discrepancy in the finding may be attributed to the peculiarity associated with number of adolescents and the belief systems in certain parts of Nigeria which cannot be compared with other developing nations especially those in Sub Sahara Africa.

The outcome of the ratio of PHF to TGF showed that it is a key determinant $\left(\mathrm{H}_{60}\right)$ and it is consistent with the apriori expectation and also corroborate the work of several researchers [96-98] who variously claimed in their studies and reflected the significance of PHF ratio in the budgets and how it affects the programmes in the health sector. In part, this also confirm Wagner's theory of increasing public expenditures as expected, which stipulated that for any country undergoing development, the public expenditure rises constantly with an upward sloping trend such that development will be accompanied by an increased share of public expenditure or allowance for social consideration in gross national product [99]. On the other hand, this result is also not completely startling, after all, the trend in the Nigerian budget has shown very dismal figures in the last three decades contrarily to the benchmark of $15 \%$ set by the WHO and other world institution to attain universal coverage. For example, this ratio in Nigeria has shown an average of $3 \%$ since 1980 to date. Consequently, between 1980 and 1990, the average PHF of the total government budget was barely $1.8 \%, 1.7 \%$ between 1991 and 2000 , and $4.76 \%$ from 2001 to 2014 . It should be noted that these percentage represents the entire health budget and not the adolescent and sexual reproductive health which comes in trickles from other health budget allocations. Moreover, the Federal Ministry of Health has earlier acknowledged that 
between 1985 and 1993 per capital investment in health has been stagnated at about US \$ 1 in comparison to the international recommended level of US \$ 34per head [100]. Indeed, this low ratio seems to have precluded the earlier projections of meeting the MDGs 4 and 5 and the "Abuja Declaration". Indeed, this also collaborate other studies which further claimed that the relationship between the ratio attributed to health finance and its effects on adolescent reproductive health transcended the public financing of the program or the public health sector to include three major dimensions of health finance coverage that must be considered -mobilization (accounting for the population coverage and financing method), risk-pooling (composition and fragmentation of its constituents) and purchasing (benefit package, provider payments mechanisms, and administrative efficiency) [101]. Undeniably, one can conclude that the regression results is actually a reflection of the Nigerian health sector since it lacked universal coverage system that would have assisted to engender a reproductive health sub-account as have been seen and practiced already in many countries of the world including those of African descent.

The impact of recurrent health expenditure on public health finance was statistically insignificant $\left(\mathrm{H}_{41}\right)$. This is not coherent with the apriori expectation. Generally, it is surprising because while there is an outcry for the low funding for the public health sector, more than $70 \%$ of this petite fund covers recurrent health expenditure such as wages, salaries and supplements. Within the periods under study the recurrent health expenditure has either doubled or tripled the capital health expenditure or even more. Specifically, from 1993 to 2014, the rates of recurrent health expenditure were between two to five or more times larger than those of capital health expenditure. For example the recurrent health expenditure for 1993, 2000, 2005, 2010 and 2014 were N2.5b, N11.7b, N50.3b, $\mathrm{N} 102.6 \mathrm{~b}$ and N216.4b; compared with those of capital health expenditure which were N352.9m, N6.5b, N21.6b, N15.6b, and $\mathrm{N} 46.3 \mathrm{~b}$ respectively [102]. This fact suggests that the recurrent health expenditure coefficient impact has a depressing effect on the meager public health finance and had been largely unproductive and inefficient, thus shrinking the funding for health projects that should impact human health, indeed, adolescent reproductive health. This incoherency corroborates the studies of Devaranja, et al., where the direction, nature and size of government expenditure affects and impacts significantly on the size and output of the economy irrespective of the sector [103]. Notwithstanding, since the regression output on recurrent health expenditure has implied otherwise depicting an insignificant result $\left(\mathrm{H}_{41}\right)$, it means that if public health finance is increased with a large chunk swooped into recurrent health expenditure, then it follows that it has no effect on the operational and running cost. If not, it will culminate into loss of lives, poor services delivery (due to factors such as poor maintenance of infrastructures and equipment resulting into drug expiry, dilapidation of equipment, and failure for referrals; absenteeism from lack of supervision), unending arrears among referral hospitals, and pressures on curative expenditures. A case might be made for recurrent health expenditure in terms of human resource personnel, however, the availability of personnel without sufficient inputs affects quality of care and leads to further loses -paying health workers who are not providing services. Likewise, recurrent health expenditure becomes suboptimal when investment in non-recurrent health expenditures becomes insufficient. To be more specific, while recurrent health expenditure seems to be draining a larger chunk of the public health finance, it however does not leave out health development expenditures or precisely off the budget expenditure such as adolescent and sexual reproductive health.

The consequence of external debts servicing to public health finance from all the test undertaken shows that that it is significance at many levels $\left(\mathrm{H}_{20}\right)$. This means that external debt servicing awfully have an impact on public health finance and absolutely consistent with a prior expectation. This is not surprising because from N31.7b in 1980 to $\mathrm{N} 258 \mathrm{~b}$ in 1990 , external debt servicing soured up to N486b in 2006. Consequently, the Nigerian government has continued to furnish several excuses for low provision of funds to other sectors because of the huge external debt service payments from time after time [104] alleging that these debt services hinders and dissuades its efforts to carry out structural and fiscal reforms that would strengthen many sectors. Surprising, of all the variables that were significant in the short-run dynamic model, only the external debt service was denoted with a negative sign. This expresses the notion that as the external debt service increases, the available public health finance decreases correspondingly and vice versa. This was reflected in the ratio of public health finance to the total government finance at its highest when external debt service payment crashed in 1998, 2002, 2005, and 2008 to 2014, compared to some other years with an increased debt service payments and matching low public health finance. Corroborating this negative impact of external debt service payments, Cohen opined that the negative effects are likely to squash other public finance investments since such payments absorb resources while reducing public expenditure including public health finance [105]. This damaging impact becomes a product of debt-induced liquidity constraints. Such constraint undoubtedly shifts the budget from the social sector such as adolescent health that would not have been neglected as it is.

Overall, the results showed some linear activities with a rather cash constraint model of public health finance. The model encapsulates the encumbrance nature of external debt servicing and the ratio of PHF to total government finance. A cursory look at the outcomes shows that the linear impact of external debt service and the ratio of PHF to total government finance is confirmed because the coefficient is statistically significant $\left(\mathrm{H}_{20}\right.$ and $\left.\mathrm{H}_{60}\right)$ in Nigeria. The external debt service presence is a strong substantiation of the crowding out and debt overhang theory in Nigeria. While all variables were somewhat significant, only two out 
of the five variable jointly capture public health finance in Nigeria.

\section{Conclusion, Recommendation, Limitations and Future Studies}

This study explored public health finance for adolescent and sexual reproductive health with particular reference to Nigeria between the periods from 1980 to 2014. The emphasis of the study was on unraveling the key determinants and the direction of causality of PHF for the utilization and allocation of the funds for adolescent and sexual reproductive health and family planning.

What determines public health finance for adolescents at the national level is an important policy question. In an attempt to respond to this question, this study formulated and specified a model for the regression analysis consisting of seven variables otherwise called determinants. PHF was regressed on these variables that formed the bedrock of the theoretical framework of the study. The VECM was used to estimate PHF and all the variables after conducting an ADF unit root test, Johanson-Juselius multivariate cointegration test for stationarity.

Overall, the model possesses a good fit as more than $80 \%$ variation in PHF in Nigeria was explained by all the variables used and can therefore be concluded that variables studied are consequential determinants of PHF in Nigeria within the period studied and therefore must be meticulously annexed by policy makers and academics. While ASRH/FP is a necessity in Nigeria, PHF for adolescent health is mainly determined by many factors specifically by the amount expended by government for public health finance to total government finance and the external debt services payments $\left(\mathrm{H}_{20}\right.$ and $\left.\mathrm{H}_{60}\right)$ in Nigeria within the study period. Three main aspects differentiate this study from previous studies. First, this study has revealed that no other studies has investigated the many issues on public health financing for ASRH/FP in Nigeria through an attempt to raise and respond to the research questions in this research. Second, previous studies on ASRH/FP rarely deliberated on the effect of an important determinant like external debt servicing. Third, the study estimated that of the variables that were significant, only external debt service was denoted with a negative sign. This reflects a damaging impact of debt-overhang which becomes a product of debt-induced liquidity constraints and such constraint neglects ASRH in the budget and shifts the budgets from the adolescent reproductive health.

In consideration of these conclusions, the research recommends that the proportion of public health finance to total government budget should be increased at all levels (Federal, State, and Local) institutions from the average of $4 \%$ to the benchmark of $15 \%$ set by the WHO in the total budgetary allocation yearly. This will undoubtedly engender robustness of the public health finance such that provisions and allocation can be extended to the ASRH/FP programmes. The Nigerian government must endeavor to reach a deal with its creditors to sort out external debt such as paying a certain amount with the others written off as they did in 2005 [106]. This will indubitably end the series of debt servicing year-inyear-out which has had a tremendous implication to PHF.

Although the specified model and the estimation in this study broke new ground from previous studies at macroeconomic level in terms of including a calorific palette of explanatory variables of adolescent reproductive health and an all-encompassing data for Nigeria as an entity, nonetheless, every model is inexorably a simplification of authenticity through which one attempt to comprehend the main characteristics of a system. Consequently, it is vital to underscore certain juncture that call for pragmatism when interpreting the outcome presented above. Firstly, it was assumed that the population of adolescent under 19, have a contemporaneous effects on PHF, the estimated equations failed to account for dynamic effects in the level of change in the adolescent age that has been considered. Second, the study was also limited to consider the influence of externalities such as economic and social factors. Perhaps, it is not impossible that the macroeconomic indicators that were applied in the analysis, including the real GDP per capital income and external debts services have been predisposed by the oscillating global economic conditions since 1980. Consequently, the total contribution of the determinants used in the contribution analysis may not have been at its optimal. Besides, it is not also impossible that the reproductive health fallacy occurred, given that the unit of analysis was the determinants chosen. In this, even though each variables annual data constituted the measurement analysis as a unit/entity - Nigeria, the variable did not consider or reflect regional or structural differences between regions in Nigeria. As a result, weights between regions could not be analyzed since structural differences were not considered between regions and no indicator that could adequately represent the differences.

The subject of this research warrants further studies not only in greater details but also in various aspects that were discussed. The set of determinants used in the estimations to depict the explanatory variables seem to be limited and further refinements to these could be made. For instance, it would be interesting to look at variations in adolescent sexual reproductive health in young men. It would be desirable to utilize more convoluted determinants of PHF for adolescent reproductive health, which utilizes quality-of-life facets into deliberation. This is because; it will be significant to account for not only a better definition of adolescent reproductive health issues but also variations in needs of each country's adolescents. The investigation on determinants of PHF for ASRH raises several questions. Can panel data also be use to elongate the available data points and to determine conventional facts advocated in past literature and whether the new signal encapsulated by this study is probable? Can a regression be use to estimate the several public health financing determinants using an all-encompassing variables for ASRH? Can instrumental variables be applied to resolve any potential endogeneity hitches in order to conduct an 
analysis with better reliability? Can weights be produce according to various variables that may represent regional depiction in relation to ASRH services? It is expected that these and related questions will be interesting channel for future research.

\section{References}

[1] Waddington C. \& Sambo C. (2014). Financing Health Care for Adolescents: A Necessary Part of Universal Health Coverage. Bulletin of the World Health Organization, 93: 57-9. Retrieved from http://dx.doi.org/10.2471/BLT.14.139741.

[2] WHO (2014). Health for the World's Adolescents: A Second Chance in the Second Decade, Geneva: WHO. Retrieved from: http://apps.who.int/adolescent/second-decade/.

[3] Singh S., Darroch J. E. \& Ashford L. S. (2014). Adding It Up: The Costs and Benefits of Investing in Sexual and Reproductive Health 2014, New York: Guttmacher Institute.

[4] Cortez R. A., Saadat, S., Marinda E. \& Oluwole O. (2015). Adolescent Sexual and Reproductive Health in Nigeria, HNPGP Knowledge Brief, 95029, World Bank Group.

[5] Sedgh G., Bankole A., Okonofua F., Imarhiagbe C., Hussain R. (2009). Meeting Young Women's Sexual and Reproductive Health Needs in Nigeria, International Family Planning Perspectives, 35 (2): 72-81.

[6] Lloyd C. B. (2005). Growing up Global: the Changing Transitions to Adulthood in DevelopingCountries. Washington, D. C.: The National Academies Press.

[7] Williamson N. (2013). State of the World Population 2013, New York: UNFPA.

[8] International Telecommunication Union, ITU (2013) BYND 2015 Global Youth Declaration. BYND 2015 Global Youth Summit, Costa Rica, 9-11 September 2013. Geneva, International Telecommunication Union, http://www.itu.int/en/bynd2015/Documents/bynd2015-globalyouth-declaration-en.pdf.

[9] Kipping R., Campbell R. M., MacArthur G. J., Gunnell D. J. \& Hickman M. (2012). Supplement on Multiple Risk Behaviour in Adolescence. Journal of Public Health, 34 (s1) i1-i2.

[10] UN (2002). Resolution S-27/2: A World Fit for Children. World Summit for Children, New York, UN.

[11] UNICEF (2013). Towards an AIDS-Free Generation Children and AIDS: Sixth Stocktaking Report, 2013, New York. UNICEF.

[12] Patel V. I., Flisher A. J., Hetrick S. \& McGorry P. (2007). Mental Health of Young People: A Global Public-health Challenge. The Lancet, 369 (9569) 1302-1313.

[13] UNFPA (2013). International Conference on Population and Development: Beyond 2014, New York, Retrieved from http://icpdbeyond2014.org/, UNFPA.

[14] The World We Want (2013). High Level Dialogue on Health in the Post-2015 Development Agenda, Gaborone, 4-6 March 201.3

Meeting report.www.worldwewant2015.org/file/320271/download/348 522.

[15] Ki-Moon B. (2013). Five-year Action Agenda: Office of the Secretary General's Envoy on Youth. New York, UN. http://www.un.org/youthenvoy/the-secretary-generalyouth/five-year-action-agenda.

[16] UN (2012). United Nations Commission on Population and Development. Resolution 2012/1 Adolescents and Youth. New York: UN.

[17] Patton G. C., Ross D. A., Santelli J. S., Sawyer S. M., Viner R. M. \& Kleinert S. (2014). Next Steps for Adolescent Health: A Lancet Commission, The Lancet, 383 (9915): 385-386, doi: 10.1016/S0140-6736(14)60039-8.

[18] UNESCO (2012). Ministerial Declaration - Preventing through Education. First Meeting of Minsters of Health and Education to Stop HIV and STIs in Latin America and the Caribbean. Santiago, UNESCO.

[19] National Health Mission (2014). Launch of RashtriyaKishorSwasthyaKaryakra and National Consultation on Adolescent Health. New Delhi, Retrieved from http://rksklaunch.in/index.html.

[20] UNFPA (2014). Framework of Actions for the follow-up to the Programme of Action of the International Conference on Population and Development Beyond 2014, New York, UNFPA, Retrieved from http://icpdbeyond2014.org/uploads/browser/files/icpd_global_ review_report.pdf.

[21] UNFPA (2012). State of the World Population 2012 by Choice, Not By Chance: Family Planning, Human Rights and Development, New York: UNFPA.

[22] Kipping R., Campbell R.M., MacArthur G.J., Gunnell D.J. \& Hickman M. (2012).Supplement on Multiple Risk Behaviour in Adolescence. Journal of Public Health, 34 (s1) i1-i2.nd Reproductive Health 2014, New York: Guttmacher Institute.

[23] UNFPA (2012). Marrying Too Young: End Child Marriage, New York: UNFPA.

[24] Darroch J. E. \& Singh S. (2013). Trends in contraceptive need and use in developing countries in 2003, 2008, and 2012: An Analysis of National Surveys, The Lancet, 381 (9879): 17561762.

[25] Olaniyan O. \& Lawason A. O. (2010). Health Expenditure and Health Status in Northern and Southern Nigeria: A Comparative Analysis Using NHA Framework, Paper presented at the $2010 \mathrm{CSAE}$ conference held at St Catherine College, University of Oxford, Oxford, UK.

[26] Berman P. \& Rose L. (1996). The Role of Private Providers in Maternal and Child Health and Family Planning services in Developing Countries. Health Policy and Planning 11: 142-55.

[27] Ichoku H. E., Fonta W. M. \& Leibbrandt, M. V. (2011). Can Out-of-pocket Health Financing be Fair? Empirical evidence from Nigeria. Asian African, Journal of Economics and Econometrics 11 (1) 89-111.

[28] Klugman B. (2004). Organising and Financing for Sexual and Reproductive Health and Rights: The Perspective of an NGO Activist Turned Donor, Reproductive Health Matters, 12 (24): 14-24. 
[29] Donaldson D. Sethi H. \& Sharma S. (2008). Vouchers to Improve Access by the Poor to Reproductive Health Services: Design and Early Implementation Experience of a Pilot Voucher Scheme in Agra District, Uttar Pradesh, India. Washington, DC: Health Policy Initiative, Task Order 1, Futures Group International.

[30] Izazola-Licea J. A., Wiegelmann, J., Ara' n C., Guthrie T., Lay P., \& Avila-Figueroa C. (2009). Financing the Response to HIV in Low-Income and Middle-Income Countries, Journal of Acquired Immune Deficiency Syndrome 52 (2).

[31] Dennis S. (2011). More Funding Needed for International Reproductive Health, Washington, DC, Population Action International.

[32] Kruk M., Galea S., Prescott M. \& Freedman L. P. (2007). Health Care Financing and Utilization of Maternal Health Services in Developing Countries. Health Policy Plan. 22 (5) 303-310.

[33] Nnennaya N., Umeh K.., Sambo, M. N., Idris S. H., Kurfi A. M. (2013). Costs and Patterns of Financing Maternal Health Care Services in Rural Communities in Northern Nigeria: Evidence for Designing National Fee Exemption Policy, International Journal of MCH and AIDS 2 (1) 163-172.

[34] Sidze E. M., Pradhan J., Beekink E., Maina T. M. \& Maina B. W. (2013). Reproductive Health Financing in Kenya: An Analysis of National Commitments, Donor Assistance, and the Resources Tracking Process, Reproductive Health Matters, 21 (42): 139-150.

[35] Senanayake P. \& Hamm S. (2004). Sexual and Reproductive Health Funding: Donors and Restrictions, The Lancet 363 (9402) 70

[36] Perkins M, Brazier E, Themmen E et al. (2009) Out-of-pocket Costs for Facility-based Maternity Care in three African Countries. Health Policy Planning 24 (4) 289-300.

[37] Rosen J. E., Sacher S., Kalangwa A. \& Kyaddondo B. (2013). Uganda: Financial Tracking of Reproductive Health Commodities. Arlington, Va.: USAID | DELIVER PROJECT, Task Order 4.

[38] WHO (2015). Tracking Universal Health coverage: First Global Monitoring Report, Geneva: World Health Organization.

[39] Dickerson D. \& Aminu A. (2013). Advocacy for Family Planning: Understanding the Budget Process in Two Nigerian States-Cross River and Zamfara. Washington, DC: Health Policy Project, Futures Group.

[40] Federal Ministry of Health (2010). Assessment Report of the National Response to Young People's Sexual and Reproductive Health in Nigeria, Abuja: Federal Ministry of Health.

[41] Greco G, Powell-Jackson T., Borghi J. \& Mills A. (2008). Countdown to 2015: Assessment of Donor Assistance to Maternal, Newborn, and Child Health between 2003 and 2006.

[42] Federal Ministry of Health, FMOH (2014). National Reproductive Health Policy and Strategy toAchieve Quality Reproductwe and Sexual Health for all Nigerians, Abuja: FMOH.

[43] Rima H. B. \&Akpan E. S. (2012). Healthcare Financing and Health outcomes in Nigeria: A State Level Study using
Multivariate Analysis, International Journal of Humanities and Social Science 2 (15) 296-309.

[44] Airhunmwunde M. E. (2015). An Appraisal of Natural Resources and Socio-economics Development: The Nigerian Case, Colombo Business Journal/International Journal of Theory and Practice, 5 (4) \& 6 (1).

[45] Federal Ministry of Health (2009). Assessment Report of the National Response to Young People's Sexual and Reproductive Health in Nigeria, Abuja: Federal Ministry of Health.

[46] Nguyen H., Snider J., Ravishankar N. \& Magvanjav O. (2011). Assessing Public and Private Sector Contributions in Reproductive Health Financing and Utilization for Six SubSaharan African Countries, Reproductive Health Matters, 19 (37), 62-74, DOI: http://dx.doi.org/10.1016/S09688080(11)37561-1.

[47] Ichoku H. E. \& Okoli C. I. (2015). Fiscal Space for Health Financing in Nigeria, African Journal of Health Economics, Epublication Ahead of Print. http://www.ajhe.org/Fiscal_Space_for_Health_Financing_in_ Nigeria_AJHE_Ichoku_and__Okoli_Jan_27.pdf.

[48] Orubuloye I. O. \& Oni J. B. (1996). Health Transition Research in Nigeria in the Era of the Structural Adjustment Programme, Health Transition Review (Supplement), 6 (301324).

[49] Central Bank of Nigeria, CBN (2001). Annual Report and Statement of Account for Year Ended 31st December, 2001, Abuja: CBN.

[50] Ichoku H. E. \& Fonta W. M. (2006). The Distributional Impact of Healthcare Financing in Nigeria: A Case Study of Enugu State. PMMA Working Paper No. 17: 3-22.

[51] UNDP (2000). Human Development Report 2000, New York: UNDP.

[52] Sachs J. D., Ahluwalia I. J., Amaoko K. Y., Aninat E., Cohen D., Diabre Z., Doryan E., et al (2001). Report of the Commision on Macroeconomics and Health, Geneva: WHO.

[53] Ogunbekun, I. O. (1991). Which Direction for Health Care in Nigeria, Health Policy and Planning, 6 (3) 254-261.

[54] World Bank (2013). Health Expenditure per Capita, WB. Retrieved From: http://data.worldbank.org/indicator/SH.XPD.PCAP.

[55] Ejughemre U. J. (2014). Accelerated Reforms in Healthcare Financing: The Need to Scale up Private Sector Participation in Nigeria, International of Health Policy Management, 2 (1), 13-19, doi: 10.15171/ijhpm.2014.04.

[56] Lu C., Schneider M. T., Gubbins P., Leach-Kemon K., Jamison D. \& Murray C. J. (2010). Public Financing of Health in Developing Countries: A Cross-National Systematic Analysis. The Lancet, 375 (9723) 1375-87.

[57] De S. \& Hatt L. (2007). Reproductive and Child Health Subaccounts to Track Resource Allocations and Flows, Presentation at Scaling-Up High Impact FP/MNCH Best Practices, Bangkok, Sept. 4.

[58] Hjorstberg C. (2001). National Health Accounts- Where are we today? Issue Paper on Health Division Document No. 6, Swedish International Development Cooperation Agency. 
[59] Willekens F. (2005). Towards a System of Reproductive Health Accounts, The Hague: Netherland Interdisciplinary Demographic Institute.

[60] Newhouse J. P. (1977). Medical-care expenditure: a crossnational survey. The Journal of Human Resources, 12 (1) 115125.

[61] Chou W. L. (2007). Explaining China's Regional Health Expenditures using Lm-type Unit Root Tests. Journal of Health Economics, (26) 682-698.

[62] Okunade A. A. \& Karakus M. C. (2001). Unit Root and Cointegration Tests: Time-series versus Panel Estimates for International Health Expenditure Models", Applied Economics (33) 1131-1137.

[63] Zweifel P., Felder S., \& Meiers M. (1999). Ageing of Population and Health Care Expenditure: A Red Herring, Health Economics, 8 (6) 485-96.

[64] Okunade A. A \& Murthy V. N. R. (2002). Technology as a 'Major Driver' of Health Care Costs: A Cointegration Analysis of the Newhouse Conjecture, Journal of Health Economics, 21 (1) $147-159$.

[65] Hitiris T. \& Posnett J. (1992). The Determinants and Effects of Health Expenditure in Developed Countries. Journal of Health Economics, 11 (2) 173-181.

[66] Okunade A. A., Karakus M. C., \& Okeke C. (2004). Determinants of Health Expenditure Growth of the OECD Countries: Jackknife Resampling Plan Estimates, Health Care Management Science, 7 (3) 173-183.

[67] Dickey D. A., \& Fuller W. A. (1981). Likelihood Ratio Statistics for Autoregressive Time Series With a Unit Root. Econometrica, 49: 1057-1072.

[68] Dickey D. A., Bell W. R. \& Miller R. B. (1986). Unit Root in Time Series Models: Tests and Implications, The American statistician, 40: 12-24.

[69] Asteriou D. \& Hall S. G. (2007). Applied Econometrics: A modern Approach using Eviews and Microfit New York: Palgrave Macmillan.

[70] Lee H. \& Lee J. (2015). More powerful Engle-Granger Cointegration Tests, Journal of Statistical Computation and Simulation, 85 (18) 3662-3678.

[71] Johansen S. (1988), Statistical Analysis of Cointegration Vectors, Journal of Economic Dynamics and Control, 12 (2-3) 231-254.

[72] Johansen S. \& Juselius K. (1990). Maximum Likelihood Estimation and Inference on Co-integration -With Application to the Demand for Money, 'Oxford Bulletin of Economics and Statistics. 52 (2) 169-210.

[73] Lien D. (2004). Co-integration and the Optimal Hedge Ratio: The General Case, The Quarterly Review of Economics and Finance, 44 (5) 654-658.

[74] Nelson C. R. \& Plosser C. I. (1982) Trends and Random Walks in Macroeconomic Time Series: Some Evidence and Implications. Journal of Monetary Economics, 10 (2) 139-162.

[75] Granger C. W. \& Newbold P. (1974). Spurious Regression in Econometric. Journal of Economic. 2 (2) 111-120.

[76] Avisjek Pal \& Prakashnit, P. K. S (2017). Practical Time
Series Analysis: Master Time Series Data Processing, Visualization, and Modeling using Python, Birmingham: Packt Publishing.

[77] Braun P. A. \& Mittnik S. (1993). Misspecifications in Vector Autoregressions and their Effects on Impulse Responses and Variance Decompositions, Journal of Econometrics, 59 (3) 319-341.

[78] Hall S. G. (1991). The Effect of Varying Length VAR Models on the Maximum Likelihood Estimates of Cointegrating Vectors. Scottish Journal of Political Economy, 38 (4) 317-323.

[79] Lütkepohl H. (1993). New Introduction to Multiple Time Series Analysis, Berlin: Springer-Verlag Berlin Heidelberg.

[80] Hafer R. W. \& Sheehan R. G. (1991). Policy Inferences Using VAR Models, Economic Inquiry, 29 (1) 44-52.

[81] Johansen S. (1988). Statistical Analysis of Cointegration Vectors, Journal of Economic Dynamics and Control, 12 (2-3) 231-254.

[82] Campos J., Ericsson N. R. and Hendry D. F. (2005). General to Specific Modeling: An Overview and Selected Bibliography, Board of governors of the Federal Reserve System International Finance discussion paper number 838 . http://www.federalreserve.gov/pubs/ifdp/2005/838/ifdp838.pd f.

[83] Draper N. R. \& Smith H. (1998). Applied Regression Analysis, New Jersey: Wiley-Interscience.

[84] Baum C. F. (2006). Testing for Serial Correlation: An Introduction to Modern Econometrics Using Stata, Texas: Stata Press.

[85] Maddala G. S. \& Lahiri K. (2009). Introduction to Econometrics, Chichester: Wiley.

[86] Achen C H. \& Shively W. P. (1995). Cross-Level Inference, University of Chicago Press.

[87] Hayashi F. (2000). Econometrics, New Jersey: Princeton University Press.

[88] Goldberger A. S. (1991). Multicollinearity. A Course in Econometrics, Cambridge: Harvard University Press.

[89] Folaran D. A. \& Awe A. A. (2014). An Assessment of Health Expenditure Determinants in Nigeria, Journal of Economics and Finance, 3 (2) 23-30.

[90] Fasoranti M. M. (2015). An Econometric Analysis of the Determinants of Government Health Expenditures in Nigeria, Journal of Empirical Economics, 4 (4) 193-206.

[91] Anyanwu J. C. (1998). An Econometric Analysis of the Determinants of Health Expenditures in Nigeria, Nigerian Journal of Economics and management Studies, $3(1,2)$ 57-71.

[92] Getzen T. E. (2007). Advancing Public Health Finance, Journal of Public Health Management \&Practice, 13 (2) 225 226.

[93] Jacobzone S. (2000). Coping with Ageing: International Challenges. Health Affair, 19 (3) 12-24.

[94] Paskawych M. (2009). The Determinants of Healthcare Expenditures: A Cross Sectional Study of The United States, ECON 421 Empirical Analysis Submitted to Dr. Jacqueline Khorassani. 
[95] Seshamani M. (2004). A Longitudinal Study of the Effects of Age and Time to Death on Hospital Costs, Journal of Healh Economics, 23: 18-26.

[96] Abbas F. \& Hiemenz U. (2011). Determinants of Public Health Expenditures in Pakistan. ZEF- Discussion Papers on Development Policy No. 158, Center for Development Research, Bonn.

[97] Olakunde B. (2012). Public Health Care Financing in Nigeria: Which Way Forward? Annals of Nigerian Medicine, 6 (1) 410, DOi: 10.4103/0331-3131.100199.

[98] Imuoghele L. E. \& Ismaila M. (2013). Determinants of Public Health Care Expenditure in Nigeria: An Error Correction Mechanism Approach, International Journal of Business and Social Science, 4 (13) 220-233.

[99] Singh S. K. (2008). Public Finance in Theory and Practice, New Delhi: S. Chand Publishing.

[100] Federal Ministry of Health, FMOH. (2004a). National Health Sector Strategic Plan for HIV \&AIDS, Abuja: Government of Nigeria.
[101] Carrin G., Mathauer I., Xua K. \& Evans D. B. (2008). Universal Coverage of health services: Tailoring its Implementation, Bulletin of the World Health Organization, 86 (11) doi: 10.2471/BLT.07.049387.

[102] Central Bank of Nigeria, CBN (2015). Annual Report and Statement of Account for Year Ended 31st December, 2015, Abuja: CBN.

[103] Devarajan S., Swaroop V., \& Zou H. (1996). The Composition of Public Expenditure and Economic Growth, Journal of Monetary Economics, 37 (1996) 313-344.

[104] Adegbite E., Ayadi F. \& Felix Ayadi, O. (2008), The impact of Nigeria's external debt on economic development, International Journal of Emerging Markets, 3 (3) 285-301. https://doi.org/10.1108/17468800810883693.

[105] Cohen D., (1993). Low Investment and Large LDC Debt in the 1980s. Am. Econ. Rev., 83 (3) 437-449.

[106] Airhunmwunde M. E. (2014). Evaluation of Governance, Potential and Socio-economic Development, 9th International Research Conference on Management and Finance, University of Colombo, Sri Lanka. 